Comm. in Asteroseismology

Vol. 152, 2008

\title{
BRITE-Austria/TUG Sat1: Launch Opportunities
}

\author{
B. Josseck ${ }^{1}$
}

${ }^{1}$ Institut für Kommunikationsnetze und Satellitenkommunikation, Universität Graz, Inffeldgasse 12, 8010 Graz, Austria

\section{Abstract}

This proceeding paper was generated using a Power-Point presentation from the workshop.

Presentation Slides

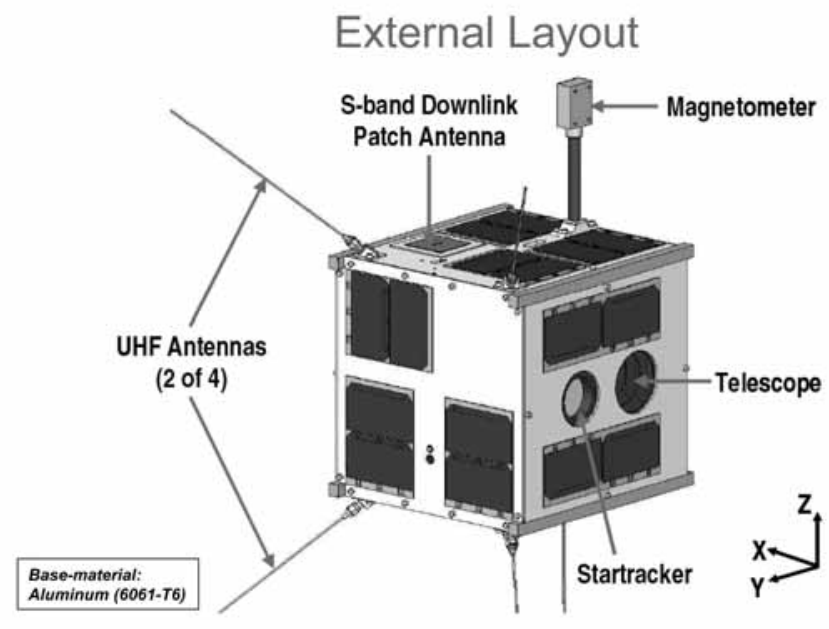




\section{BRITE-Austria - Baseline Orbits}

BRITE is designed for any low earth orbit in view of the ground stations to maximize launch flexibility. Typically, the following orbits are used for analysis:

- Dawn-Dusk Sun-Synchronous (minimum eclipse): hot case for thermal analysis

- Noon-Midnight Sun-Synchronous (maximum eclipse): cold case for thermal analysis, worst power conditions

- $900 \mathrm{~km}$ altitude orbit for link budgets

- $550 \mathrm{~km}$ altitude orbit for atmospheric drag and Doppler

The launch (and consequently the orbit) of BRITE is unknown at this time. The spacecraft will be launched as a secondary or tertiary payload, hopefully in late 2008.

\section{Boundary Conditions}

\section{Loads \& Accelerations}

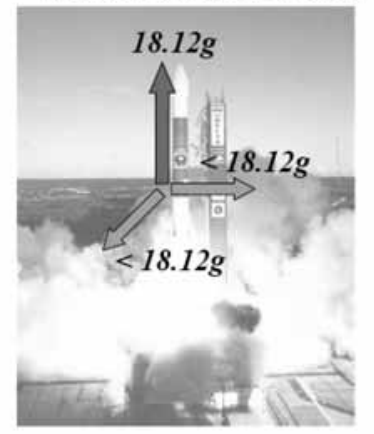

$22.65 g$

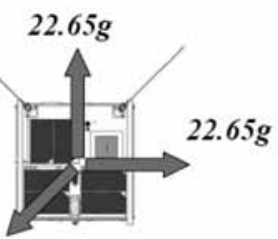

Delta II Worst Case Acceleration

$+25 \%$ Margin 


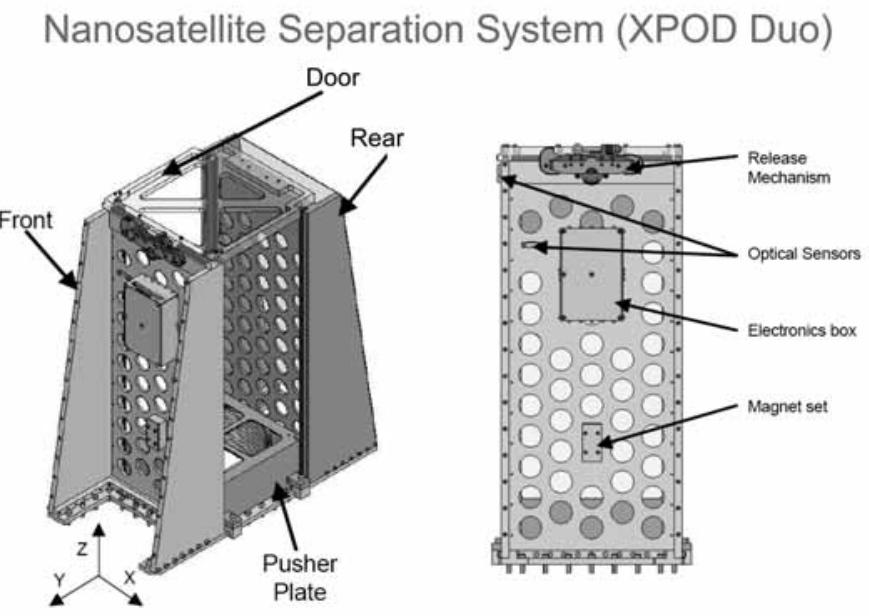

Nanosatellite Separation System (XPOD Duo)

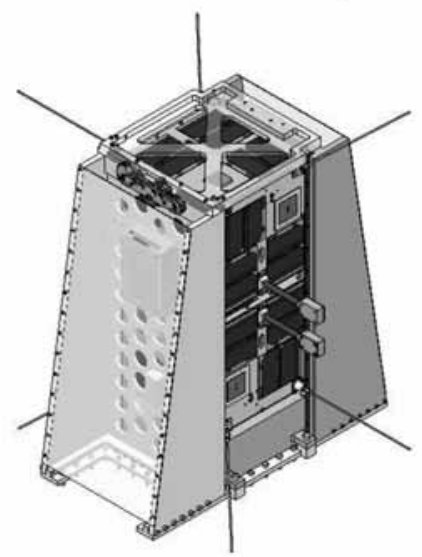

- Is designed to accommodate two 6 $\mathrm{kg}, 20 \times 20 \times 22 \mathrm{~cm}$ spacecrafts (antennas, booms etc. pre-deployed)

- Outer dimensions: $\sim 24 \times 49 \times 55 \mathrm{~cm}$

- Mass: $+12 \mathrm{~kg}$ 


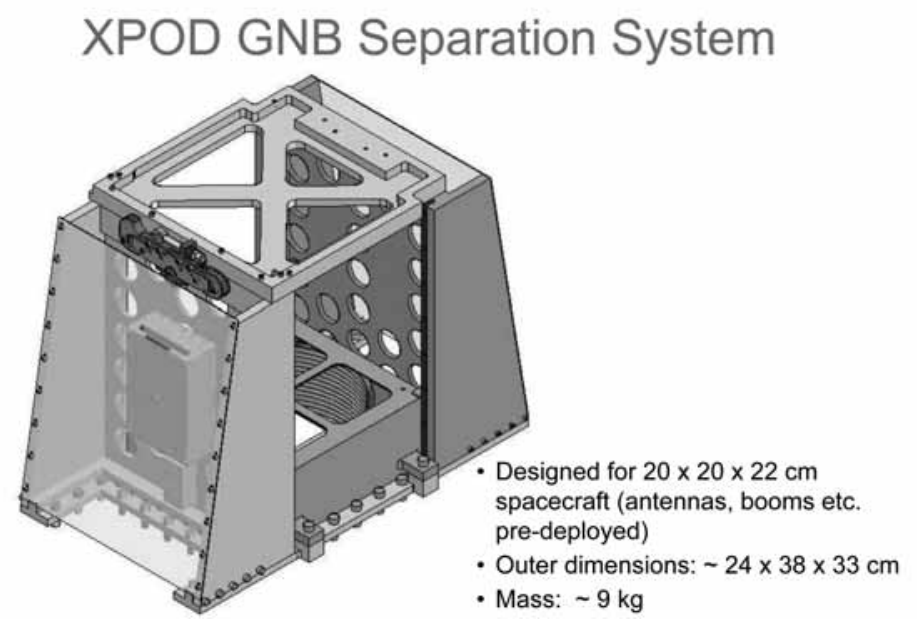

Release Mechanism

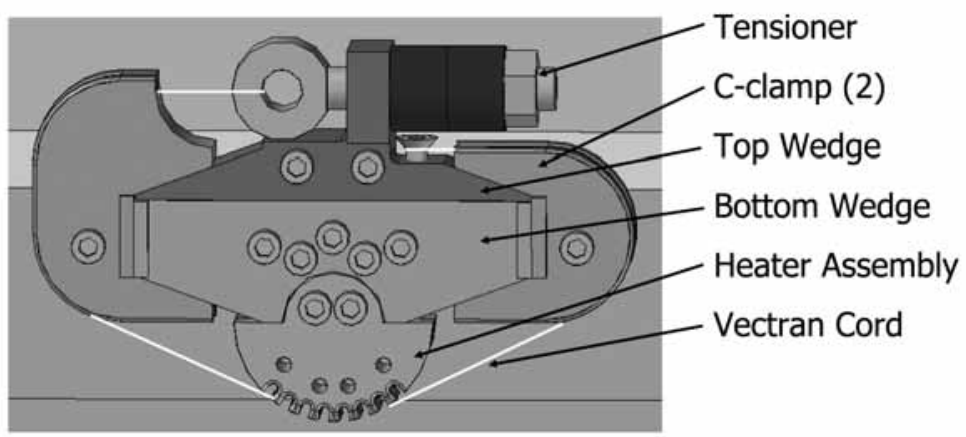


Mechanism Release Sequence

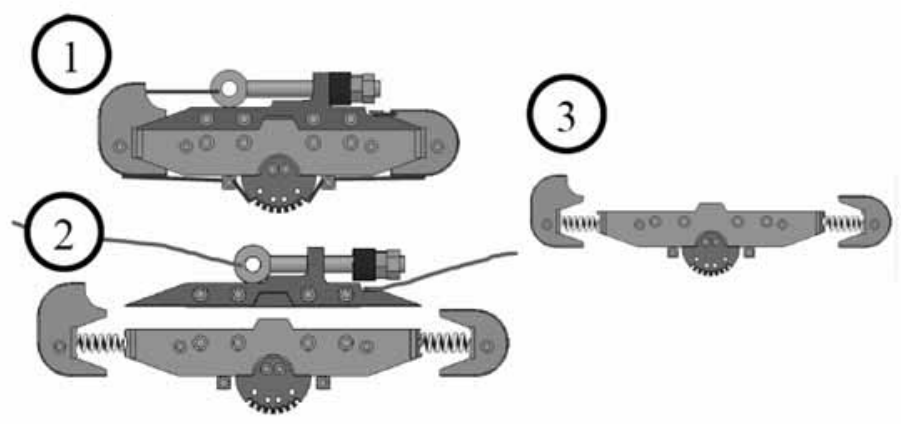

Release Sequence

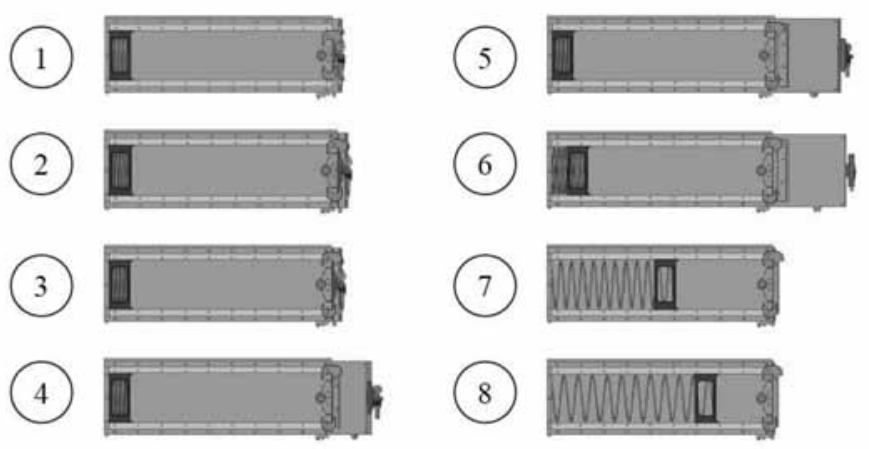




\section{Deployment Principle}

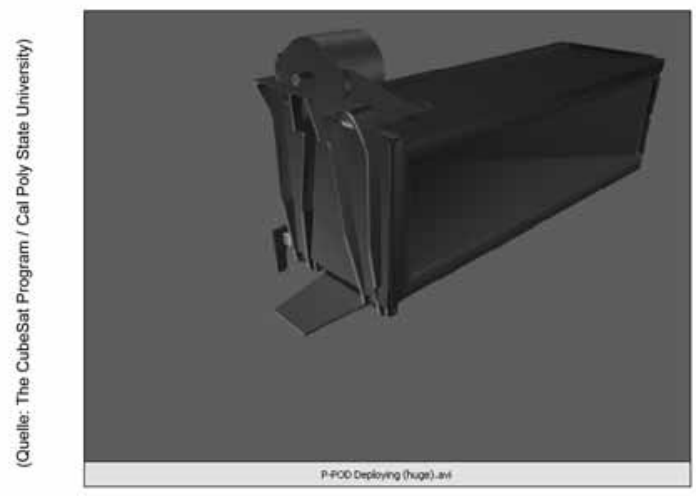

\section{Launch Opportunities}

Launcher:

- DNEPR

- ROKOT

- KOSMOS

- ARIANE V

\section{Launch Sites:}

- Plesetsk (Ru)

- Baikonur (Kas)

- Kourou (F)

\section{Launch Costs:}

- ca. $€ 10.000$,- bis $20.000,-/$ kg

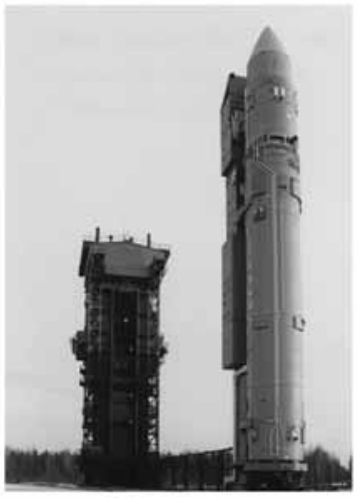

ROKOT (Khrunichev) 


\section{Launch Opportunities}

- AGIIF, Vienna, April 23, 2007: Signing of a MOU between the Russian and the Austrian side (article 7 - providing support with launch of TUGSAT-1)

- In our first contacts, Roscosmos suggested a Dnepr launch.

- Kazakhstan, July 26, 2006: 18 Russian and foreign-made microsatellites were destroyed when a civilian version of the heavy R$36 \mathrm{M} 2$ crashed shortly after liftoff, due to a first stage engine shutdown.

- On April 17 Russia has successfully launched a Dnepr carrier rocket. 16 foreign (Egyptian, Saudi satellites) and additional P-Pod and Cube-Sat micro-satellites were delivered and successfully deployed into $640 \mathrm{~km}$ sun-synchronous orbit (being the $8^{\text {th }}$ commercial launch).

- Currently the reliability factor for the rocket (160 launches in SS18 and Dnepr configuration) is 0,97

\section{Russian rocket fails (July 26, 2006)}

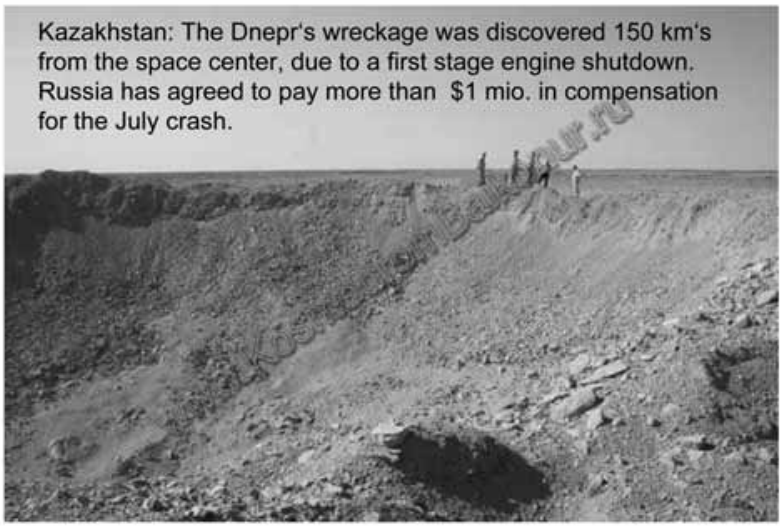




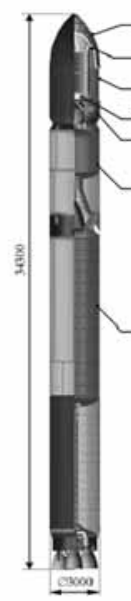

\section{DNEPR LV}

\section{DNEPR Launch}

Civilian version of the heavy R-36M2 (SS-18 Satan) intercontinental ballistic missile

\section{Quelle:}

Kosmotras

DNEPR LV

Launch weight $211 \mathrm{t}$

Propellant amyl + heptyl

Stages $\quad 3$

ø $3 \mathrm{~m}$

LV length $\quad 34 \mathrm{~m}$

Reliability $\quad 0.97$

Payload $\quad 400 \mathrm{~kg}(800 \mathrm{~km})$

$1400 \mathrm{~kg}(600 \mathrm{~km})$

Orbit inclination 50,$5 ; 64,5 ; 87,3 ; 98,0 \mathrm{deg}$.

Operational loads:

Axial quasi-static g-load...up to 7.5

Lateral quasi-static g-load...up to 0.8

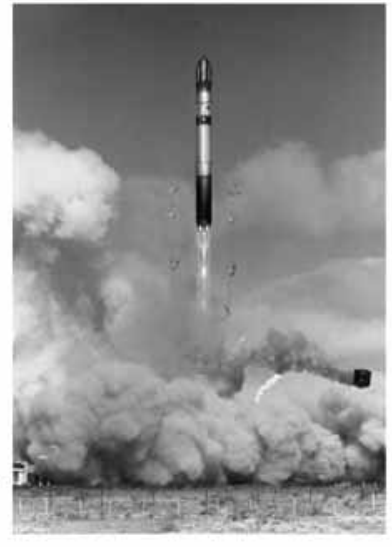

\section{Dnepr - Liftoff Diagram}

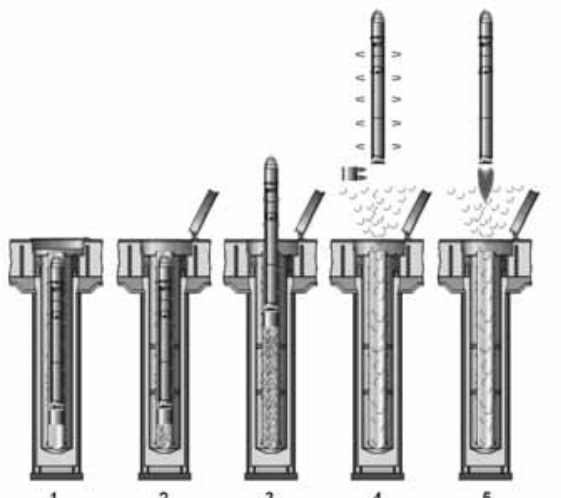

Steam eject from the launch silo using standard launch sequence. 


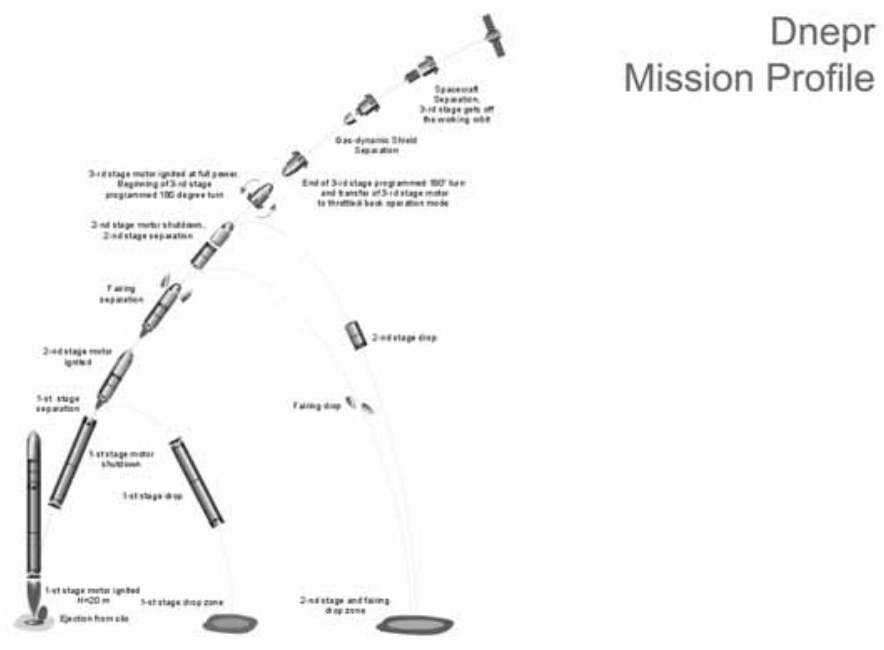

Dnepr Application for Space Missions

Dnepr Cluster Launch Capability for Small and Microsatellites

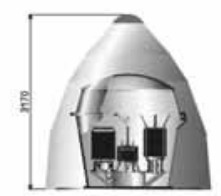

Space Head with Encapsulated Payload Module

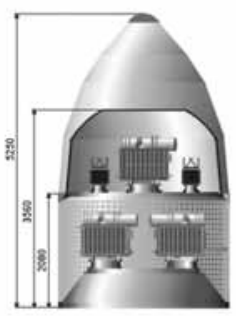

Double-tier Configuration of Space Head

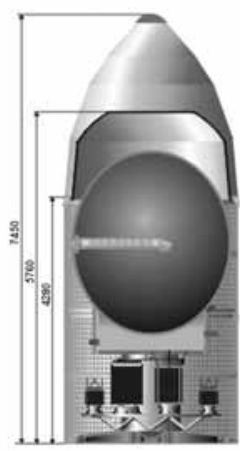

Space Head configuration with a big and a group of small spacecrafte 


\section{DNEPR - Integration}

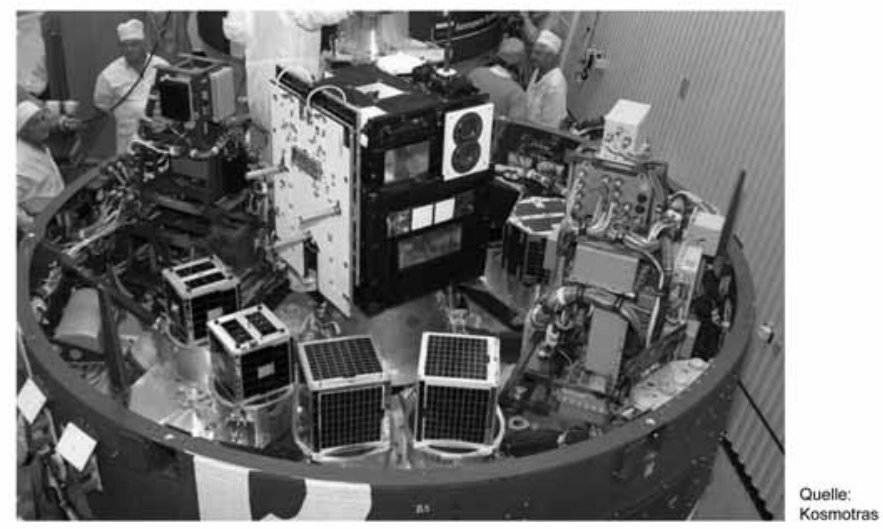

Dnepr - Launch Preparation
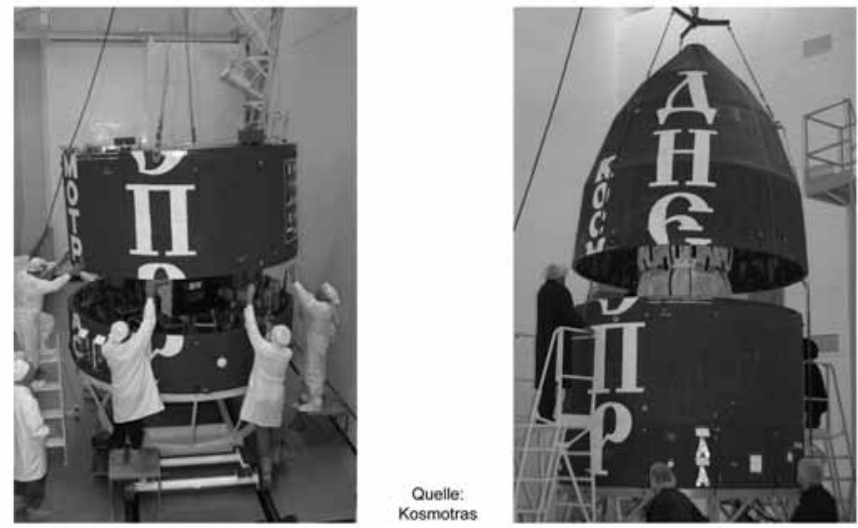

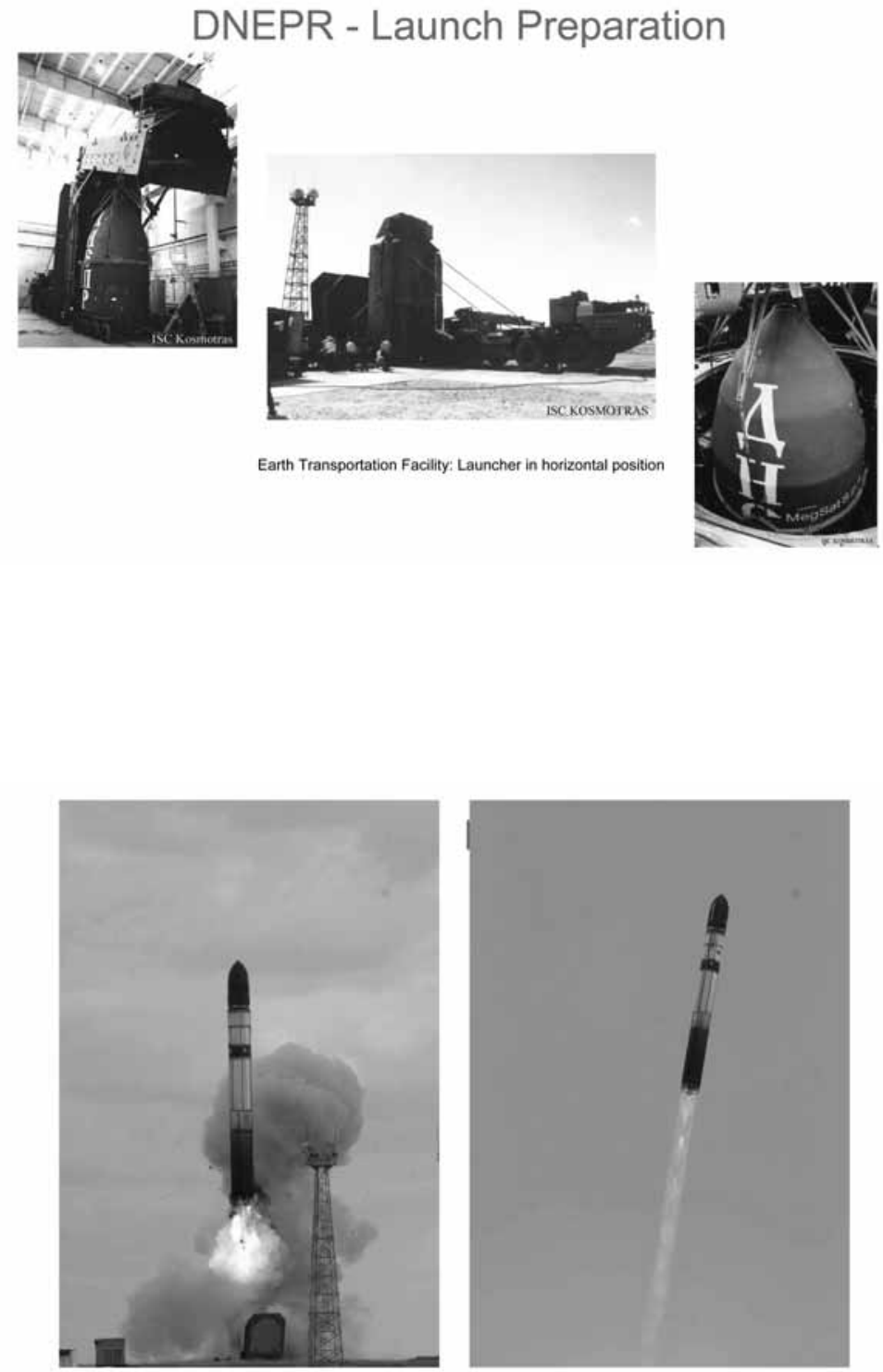


\section{DNEPR - Deployment Simulation}

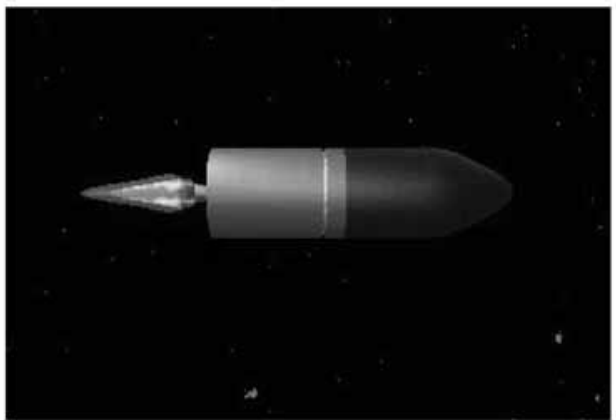

(Quelle: The CubeSat Program / Cal Poly State University)

\section{Informations}

www.tugsat.at oder www.tugsat.com

www.iks.tugraz.at

Contact TUGSAT-Team:

tugsat@tugraz.at 